\title{
SMAD4 Gene Methylation May Be Effective in Adenocarcinoma Lung Cancers
}

\author{
(1) Metin Budak
}

Trakya University Faculty of Medicine, Department of Biophysics, Edirne, Turkey

Trakya University, Molecular Research Laboratory, Prof. Mirko Tos Ear and Hearing Research Center, Edirne, Turkey

Cite this article as: Budak M. SMAD4 Gene Methylation May Be Effective in Adenocarcinoma Lung Cancers. J Acad Res Med 2021;11(1):86-89

\begin{abstract}
Objective: In this study, we aimed to investigate the effect of promoter region methylation of small mothers against decapentaplegic 4 (SMAD4) gene in adenoma type lung cancer cases. Adenocarcinoma and squamous type carcinomas are the most common types of lung cancer. SMAD4 gene is an intracellular signal protein. The protein of this gene, which is one of the transcription factors, functions in tissue homeostasis during embryonic development and has effects in the cancer process.

Methods: In this retrospective study, a total of 40 samples including 20 paraffin-embedded tumor tissues of 20 patients with adenocarcinoma lung cancer and normal lung tissue of the same patients were included. After DNA isolation from this paraffin-embedded adenocarcinoma lung tumor tissue and its normal counterparts, methylation specific polymerase chain reaction followed by agarose gel imaging methods were applied to investigate the SMAD4 promoter methylation after bisulfite modification.

Results: As a result of our study, an increased presence of methylation in the promoter region of the SMAD4 gene in the tumor tissue of a total of 12 (60\%) of 20 adenocarcinoma cases compared to normal tissue was detected. A statistically significant increase in methylation rate of approximately $25-45 \%$ was found in tumor tissues of these cases compared to normal tissues $(p<0.05)$.

Conclusion: As a result of our study, we suggested that SMAD4 gene methylation may be a tumor marker for lung cancers and may contribute to the development of cancer by inhibiting SMAD4 protein expression by gene methylation and disrupting the intracellular signal pathway.

Keywords: SMAD4, DNA methylation, lung cancer, adenocarcinoma
\end{abstract}

\section{INTRODUCTION}

Lung cancer is the first cancer to cause death in men and the second cancer in women among all types of cancer. Approximately 1.3 million people die from lung cancer each year in the world. However, with the newly developed lung cancer treatment methods, the average life span and quality have started to increase relatively (1). Approximately $80 \%$ of lung cancers with a high mortality rate worldwide are reported as non-small-cell lung cancer (NSCLC). NSCLC have two subtypes, adenocarcinoma and squamous, and are classified histopathologically as adenocarcinoma and squamous cellular carcinoma. Adenocarcinomas and squamous carcinomas represent approximately $50 \%$ of all $\operatorname{NSCLC~}(1,2)$.

Small mothers against decapentaplegic 4 (SMAD4) is a gene that synthesizes a protein product that carries chemical signals from the cell surface towards the nucleus. This signaling pathway works through the transforming growth factor (TGF)-pathway and can be affected by the cell's peripheral environment. Signal formation begins with the binding of TGF-beta (TGF- $\beta$ ) protein to the corresponding receptor on the cell surface, and this event provides

ORCID ID of the author: M.B. 0000-0002-5968-2048.

Corresponding Author/Sorumlu Yazar: Metin Budak,

E-mail: genomicdna2@yahoo.com
Received Date/Geliş Tarihi: 13.01.2021 Accepted Date/Kabul Tarihi: 09.03.2021

(C) Copyright 2021 by University of Health Sciences Turkey, Gaziosmanpaşa Training and Research Hospital. Available on-line at www.jarem.org 
the activation of SMAD group proteins (3). SMAD proteins bind to SMAD4 to form a protein complex, and this new complex that is formed transmits the signal by moving towards the cell nucleus. It also controls the growth and activation of tumor suppressor genes in the nucleus (4).

Methylation is a process characterized by the addition of a methyl group to the 5-carbon cytosine in the $\mathrm{CpG}$ nucleotide sequences, particularly in the promoter regions of genes. Studies have shown that a significant portion of mammalian genomes are methylated $(5,6)$. Methylation reactions in genes affect gene expression and therefore genes can be inactivated or activated. In this study, in order to determine the contribution of the SMAD4 gene to the formation of lung cancers, we aimed to show the changes in the stage of transformation from normal tissue to tumor by determining the potential cellular methylation in the promoter region of normal and tumor tissues in adenoma type lung cancers with methylation specific polymerase chain reaction (MSP) method. In this respect, our study is the first study in the literature.

\section{METHODS}

Our study is a cross-sectional retrospective study and patient consent was not obtained. For this study, 10 histologically confirmed advanced stages (stage 3); 5 sections from early stage (stage 1) and middle stage (stage 2) lung tumor tissues with adenocarcinoma and 5 sections from the outermost parts of the surgical margins as normal lung tissue of the same cases, $(10$ pieces per case) a total of 200 slice slide tissue samples belonging to 20 cases were prepared in formalin-fixed paraffin-embedded tissue blocks (7). The clinical characteristics of the patients are shown in Table 1. The number of samples to be studied was determined by power analysis, and all cases used in this study were used in the paraffin tissue archive of patients diagnosed with lung cancer between 2007-2018 in Trakya University Pathology Department. Pathological evaluation of all tissues was made in pathology department. This study was conducted with the permission of the Trakya University Local Ethics Committee (approval number: 05/21, approval date: 27.02.2013).

\section{Genomic DNA Isolation and Bisulfite Modification from Paraffin Embedded Tissues}

As stated before, sections were obtained from selected tissues and were scraped from the slides into tubes and their DNAs were isolated as stated in the literature (8). These DNAs were then analyzed by spectrophotometric method after determining the amount of DNA at $280 \mathrm{~nm}$ and $260 \mathrm{~nm}$ wavelengths; and samples were stored at $+4{ }^{\circ} \mathrm{C}$ for further analysis. Bisulfite modifications of DNAs were made in accordance with the EpiJET Bisulfite Conversion Kit and Protocol (Thermo Fisher Scientific-USA) $(7,8)$.

\section{Methylation Analysis of the SMAD4 Promoter}

With the sodium bisulfite modification of genomic DNA, all unmethylated cytosines in DNA are converted to thymine, but this reaction does not affect cytosines in methylated state, creating a potential sequence difference. After this chemical modification of
DNA, DNA samples were used for methylation analysis of SMAD4 gene. The MethPrimer V1.1 beta program was used (available at www.urogene.org) to identify potential methylation sites and methylation-specific primer sequences for the SMAD4 gene sequence (9).

\section{Methylation Specific Polymerase Chain Reaction Method}

The methylation specific primers for the promoter of the SMAD4 gene region are as follows: Forward 5': GTAATAATACGGTTTTGGTCGTC-3', Reverse: 5'-TCCCACCCCC TAAACGACCGCG-3', product size: 164 base pair (bp), Tm: $77.4{ }^{\circ} \mathrm{C}$, SMAD4 gene specific primers of unmethylated used for the promoter region were as follows: Forward: 5'- GTAATAATATGGTTTTGGTTGTT-3', reverse: 5'CTCCCACCCCCTAAACAACCACA-3', product size: 163 bp, Tm: $72.3{ }^{\circ} \mathrm{C}$. The polymerase chain reaction (PCR) conditions have been created from $95^{\circ} \mathrm{C} 45^{\prime}, 55^{\circ} \mathrm{C} 30^{\prime}, 72^{\circ} \mathrm{C} 30^{\prime} \times 35$ cycles following initiation for $10^{\prime}$ at $95^{\circ} \mathrm{C}$ and finally $5^{\prime}$ termination at $72{ }^{\circ} \mathrm{C}$. Methylated and unmethylated PCR media; PCR buffer $1 \mathrm{x}$, $\mathrm{MgCl}_{2}: 2 \mathrm{mM}$, DMSO: 5\% (v/v), dNTP: $12.5 \mathrm{mM}$, primer forward: 10 $\mathrm{nM}$, primer reverse: $10 \mathrm{nM}$, taq polymerase: $1 \mathrm{U}(5 \mathrm{U} / \mu \mathrm{L})$. Template DNA $100 \mathrm{ng}$ was completed with up to $50 \mu \mathrm{L}$ of $\mathrm{dH}_{2} \mathrm{O}$. Methylated and unmethylated human DNAs were used as positive and

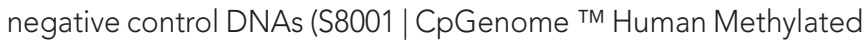
and Unmethylated DNA Standard Set). These DNAs were bisulfite modified before PCR. PCR with these modified DNA samples was performed using methylation-specific and non-methylationspecific primers. Later, PCR products were evaluated for $2 \%$ agarose gel under ultraviolet light (9), tumors and normal tissues were compared for methylation, and methylation rates were determined.

\section{Statistical Analysis}

Statistical analysis of the study was performed using the SPSS 20 program (IBM Corp, Armonk, NY, USA). Continuous variables were expressed as mean \pm standard deviation and qualitative variables as percentages. Statistical analysis of methylation specific PCR results was performed and the results of the experimental and control groups were compared with the $\chi^{2}$ test, $p<0.05$ was considered statistically significant (10).

\section{RESULTS}

1-3 $\mu \mathrm{L}$ of bisulfite modified DNA was used for each methylated and un-MSP. MSP and un-MSP products were stained with ethidium bromide and evaluated on a 2 percent agarose gel (Figure $1 \mathrm{~A}-\mathrm{B}$ ). The expected band size in the promoter of the SMAD4 gene was 163-164 bp for MSP and un-MSP (Figure 1) (11). As a result, SMAD4 promoter methylation was present in approximately 12 (60\%) of adenocarcinoma tumors and un-methylation was 3-10\%, whereas in normal lung tissues, $70 \%$ un-methylation and approximately $20 \%$ methylation were observed $(p<0.05)$. When evaluated according to tumor stages, $40 \%$ of the first stage tumors (in 4 samples), $87.5 \%$ of the second stage tumors (6 samples) and $66 \%$ 
of the third stage tumors (in 2 samples) were observed to increase in methylation (Table 1).

\section{DISCUSSION}

The SMAD4 gene, located on chromosome 18q21, is known somatically as a candidate tumor suppressor gene in many pancreatic and colorectal tumors. It has been shown that changes in the SMAD4 gene that cause it to inactivate by mutation mechanisms such as deletion have been shown to be effective in pancreatic and colorectal cancers (11). For these reasons, SMAD4 methylation has been studied primarily in colorectal and pancreatic cancers. MSP is the main method used to investigate

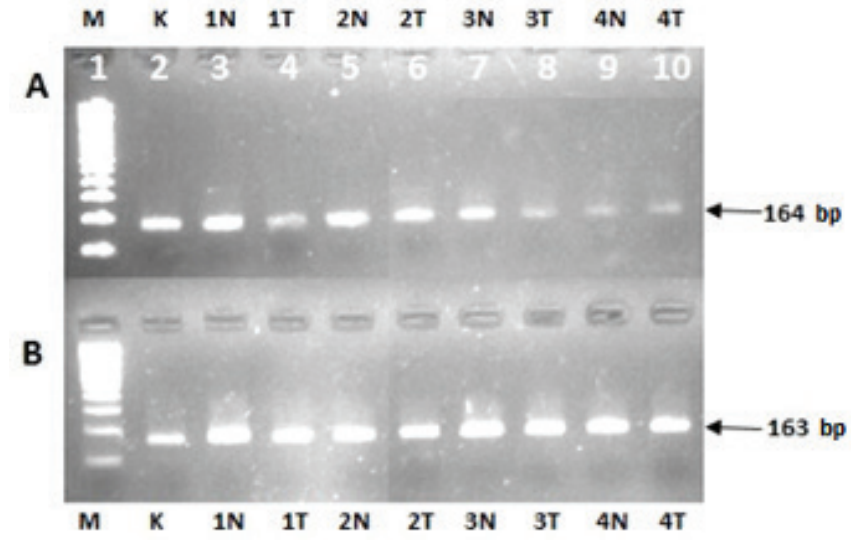

Figure 1. A. Un-methylation specific polymerase chain reaction (PCR) result for SMAD4 gene, line 1: M: 100 bp marker, line 2: (+) control DNA, normal and tumor pairs for each case line 3-11. B. Specific PCR results for SMAD4 gene methylation, line 1: M: 100 bp marker, line 2: (+) control DNA, normal and tumor pairs for each case line 3-11

$\mathrm{N}$ : normal, T: tumor

\begin{tabular}{|c|c|c|c|c|c|}
\hline \multicolumn{2}{|c|}{$\begin{array}{l}\text { Table 1. Clinical } \\
\text { adenocarcinoma }\end{array}$} & \multicolumn{2}{|c|}{ characteristics of } & \multicolumn{2}{|c|}{ patients with } \\
\hline & $\begin{array}{l}\text { Normal } \\
\text { case } \\
(n=20)\end{array}$ & $\begin{array}{l}\text { Methylation } \\
\text { normal } \\
\text { tissue }\end{array}$ & $\begin{array}{l}\text { Tumor } \\
\text { case } \\
(n=20)\end{array}$ & & $\begin{array}{l}\text { Methylation } \\
\text { tumor tissue }\end{array}$ \\
\hline & n (\%) & n (\%) & n (\%) & $\%$ & n (\%) \\
\hline $\begin{array}{l}\text { Age, year } \\
(\text { Mean } \pm S D)\end{array}$ & $58 \pm 7$ & - & - & - & - \\
\hline$\leq 53$ & $9(45)$ & - & $9(45)$ & 45 & - \\
\hline$>59$ & $11(55)$ & - & $11(55)$ & 55 & - \\
\hline \multicolumn{6}{|l|}{ Gender } \\
\hline Female & $5(25)$ & - & $5(25)$ & 25 & - \\
\hline Male & $15(75)$ & - & $15(75)$ & 75 & - \\
\hline \multicolumn{6}{|l|}{ Phase } \\
\hline 1 & - & - & 10 & 50 & $4(40)$ \\
\hline 2 & - & - & 7 & 35 & $6(85.7)$ \\
\hline 3 & - & - & 3 & 15 & $2(66.6)$ \\
\hline
\end{tabular}

gene methylations and has been used successfully in many cancer and other disease groups (12). Since there is no study in the literature showing the SMAD4 methylation status in lung cancers, we examined the SMAD4 promoter region using the MSP method. SMAD4 may be a good chemotherapeutic option, especially because of its role in transcriptional function (13). There is a relationship between SMAD4 expression and associated TGF- $\beta$ and increased functional gene expression and activation of oncogenesis signaling pathways, especially in cancer development $(10,11)$. Our research has shown that SMAD4 methylations can be seen in lung adenocarcinoma. Perhaps in this way, it could be one of the reasons for SMAD4 gene inactivation and, in conjunction with other active genes, reduced life expectancy in lung cancers. There is limited information on this subject in the literature. In the light of this information, it shows the potential importance of activating or inactivating oncogenesis pathways in cancer treatments. Studies examining both epigenetic properties of this gene and explaining epigenetic inhibition mechanisms may be interesting in the search for new cancer chemotherapy agents $(10,11,14)$.

However, even from this aspect alone, our study showed that SMAD4 methylation occurs in one of the most common lung cancer types, namely adenocarcinoma lung cancers. Our study is a rare study showing that SMAD4 promoter methylation may be associated with adenocarcinoma lung cancers.

\section{Study Limitations}

The fact that SMAD4 gene methylation and SMAD4 gene expression in RNA and protein levels could not be studied in tumor and normal lung tissues in our study is a limitation.

\section{CONCLUSION}

More research is needed on gene expression and pathways for SMAD4 in lung cancers. In the near future, the methylation sites of SMAD4 promoters promise to be therapeutic targets in lung cancers and other types of cancer where this gene is known to play a role. We believe that this may increase the effectiveness of available cancer treatments and have positive effects on life expectancy/quality of life for cancer patients.

Acknowledgement: I thanked to Dr. Ömer Yalçın for pathology examinations.

Ethics Committee Approval: This study was conducted with the permission of the Trakya University Local Ethics Committee (approval no: 05/21, approval date: 27.02 .2013 ).

Informed Consent: Our study is a cross-sectional retrospective study and patient consent was not obtained.

Peer-review: Externally peer-reviewed.

Financial Disclosure: The author declared that this study has received no financial support.

\section{REFERENCES}

1. Pinto R, Petriella D, Lacalamita R, Montrone M, Catino A, Pizzutilo P, et al. KRAS-driven lung adenocarcinoma and $b$ cell infiltration: novel insights for immunotherapy. Cancers (Basel) 2019; 11: 1145. 
2. Gan Z, Zou Q, Lin Y, Huang X, Huang Z, Chen Z, et al. Construction and validation of a seven-microRNA signature as a prognostic tool for lung squamous cell carcinoma. Cancer Manag Res 2019; 11: 5701-9.

3. Miyaki M, Kuroki T. Role of Smad4 (DPC4) inactivation in human cancer. Biochemical and b67uj8iophys Res Commun 2003; 306: 799-804.

4. Korc M. Smad4-TGF-B signaling pathways in pancreatic cancer pathogenesis. Pancreatic Cancer. New York: Springer; 2018. p. 431-55.

5. Ramsahoye $B H$, Biniszkiewicz D, Lyko F, Clark V, Bird AP, Jaenisch R. Non-CpG methylation is prevalent in embryonic stem cells and may be mediated by DNA methyltransferase 3a. Proc Nat Acad Sci U S A 2000; 97: 5237-42.

6. Cho S, Lee JH, Cho SB, Yoon KW, Park SY, Lee WS, et al. Epigenetic methylation and expression of caspase 8 and survivin in hepatocellular carcinoma. Pathol Int 2010; 60: 203-11.

7. Budak M. Methylation of the promoter of survivin gene may affect immunohistochemical expression of survivin protein in lung cancers. Cerrahpaşa Medical Journal 2019; 43: 44-9.

8. Yalcin O, Budak M. Un-methylation of the survivin gene has no effect on immunohistochemical expression of survivin protein in lung cancer patients with squamous cell carcinoma. Bratisl Lek Listy 2017; 118: 160-3.

9. Li L-C, Dahiya R. MethPrimer: designing primers for methylation PCRs. Bioinformatics 2002; 18: 1427-31.

10. Chaopatchayakul $P$, Jearanaikoon $P$, Yuenyao $P$, Limpaiboon T. Aberrant DNA methylation of apoptotic signaling genes in patients responsive and nonresponsive to therapy for cervical carcinoma. Am J Obstet Gynecol 2010; 202: 281.

11. Aitchison AA, Veerakumarasivam A, Vias M, Kumar R, Hamdy FC, Neal DE, et al. Promoter methylation correlates with reduced Smad4 expression in advanced prostate cancer. Prostate 2008; 68: 661-74.

12. Roth $S$, Laiho $P$, Salovaara $R$, Launonen $V$, Aaltonen LA. No SMAD4 hypermethylation in colorectal cancer. Br J Cancer 2000; 83: 1015-9.

13. Marini KD, Croucher DR, McCloy RA, Vaghjiani V, Gonzalez-Rajal A, Hastings JF, et al. Inhibition of activin signaling in lung adenocarcinoma increases the therapeutic index of platinum chemotherapy. Sci Transl Med 2018; 10: eaat3504. doi: 10.1126/scitransImed.aat3504.

14. Budak M, Ozkan U, Yildiz M. Identification of potential methylation regions of the smad4 mrna and determining primer sequences for mspcr with the 'methprimer'program. Int J Genet Genom 2019; 7: 55-9. 